randomized trial of immunotherapy with or without stereotactic radiosurgery in appropriate patients. We also contend that these results further reinforce the case for careful screening of high-risk, early-stage disease to detect smallvolume CNS relapse with the use of magnetic resonance imaging. Finally, a better understanding of the mechanisms of metastatic spread of melanoma to the brain and of the unique CNS immune microenvironment is necessary to further improve the outcomes of these patients. Translational studies that facilitate tissue sampling after death (e.g., the PEACE [Posthumous Evaluation of Advanced Cancer Environment] Study; ClinicalTrials.gov number, NCT03004755) could play a critical role in informing this understanding.

What is the broader relevance of these data? Unquestionably, they show that checkpoint inhibitors can be as efficacious for CNS metastases as they are for extracranial metastases from melanoma. Therefore, we would recommend additional, larger trials involving patients with CNS metastases not just from melanoma but also from kidney, lung, and other cancers in which checkpoint inhibitors are active. Such patients should no longer generally be excluded from clinical trials.
Disclosure forms provided by the authors are available with the full text of this editorial at NEJM.org.

From the Renal and Skin Units, Royal Marsden NHS Foundation Trust (S.T., J.L.), and the Translational Cancer Therapeutics Laboratory, Francis Crick Institute (S.T.) — both in London.

1. Sampson JH, Carter JH Jr, Friedman AH, Seigler HF. Demographics, prognosis, and therapy in 702 patients with brain metastases from malignant melanoma. J Neurosurg 1998;88:11-20.

2. Gray-Schopfer V, Wellbrock C, Marais R. Melanoma biology and new targeted therapy. Nature 2007;445:851-7.

3. Pardoll DM. The blockade of immune checkpoints in cancer immunotherapy. Nat Rev Cancer 2012;12:252-64.

4. Ugurel S, Röhmel J, Ascierto PA, et al. Survival of patients with advanced metastatic melanoma: the impact of novel therapies — update 2017. Eur J Cancer 2017;83:247-57.

5. Davies MA, Saiag P, Robert C, et al. Dabrafenib plus trametinib in patients with $\mathrm{BRAF}^{\mathrm{V} 600}$-mutant melanoma brain metastases (COMBI-MB): a multicentre, multicohort, open-label, phase 2 trial. Lancet Oncol 2017;18:863-73.

6. Goldberg SB, Gettinger SN, Mahajan A, et al. Pembrolizumab for patients with melanoma or non-small-cell lung cancer and untreated brain metastases: early analysis of a non-randomised, open-label, phase 2 trial. Lancet Oncol 2016;17:976-83.

7. Margolin K, Ernstoff MS, Hamid O, et al. Ipilimumab in patients with melanoma and brain metastases: an open-label, phase 2 trial. Lancet Oncol 2012;13:459-65.

8. Long GV, Atkinson V, Lo S, et al. Combination nivolumab and ipilimumab or nivolumab alone in melanoma brain metastases: a multicentre randomised phase 2 study. Lancet Oncol 2018;19:672-81.

9. Tawbi HA, Forsyth PA, Algazi A, et al. Combined nivolumab and ipilimumab in melanoma metastatic to the brain. $\mathrm{N}$ Engl $\mathrm{J}$ Med 2018;379:722-30.

DOI: 10.1056/NEJMe1807752

Copyright (๑) 2018 Massachusetts Medical Society.

\title{
Finding Better Ways to Prevent Postpartum Hemorrhage
}

\author{
Haleema Shakur-Still, M.Sc., and Ian Roberts, Ph.D.
}

Postpartum hemorrhage is the leading cause of maternal death in low-income countries. ${ }^{1}$ Although moderate bleeding after childbirth is not problematic in most healthy mothers, it can be life-threatening in mothers with clinically significant anemia, and severe bleeding can be rapidly fatal. Prevention of excessive postpartum bleeding is essential.

The administration of drugs to contract the uterus (uterotonic agents) immediately after delivery is the cornerstone of strategies to prevent excessive postpartum bleeding. ${ }^{2}$ The uterine smooth muscle is believed to act as a living ligature that compresses bleeding blood vessels, stemming the flow of blood. Although there are remarkably few high-quality trials comparing oxytocin with placebo, ${ }^{3}$ oxytocin has become the standard uterotonic agent and is widely recommended in guidelines. ${ }^{2}$ However, oxytocin is heatsensitive and loses potency in hot climates.

This issue of the Journal includes reports of two landmark randomized trials of strategies to prevent postpartum bleeding. The Carbetocin Haemorrhage Prevention (CHAMPION) trial, conducted by Widmer et al., ${ }^{4}$ was a randomized, noninferiority trial evaluating the intramuscular injection of oxytocin as compared with carbetocin, a synthetic analogue of oxytocin that does not require cold-chain transport and cold storage, ${ }^{5}$ immediately after vaginal delivery. The trial 
had two primary outcomes: the proportion of women with blood loss of at least $500 \mathrm{ml}$ or the use of additional uterotonic agents, and the proportion of women with blood loss of at least $1000 \mathrm{ml}$. According to the protocol, the first outcome was the criterion for regulatory approval, whereas the second was for evaluating clinical effectiveness and for the potential inclusion of heat-stable carbetocin in future World Health Organization (WHO) guidelines and the Model List of Essential Medicines.

Noninferiority was shown for the first but not the second primary outcome. Despite the inclusion of nearly 30,000 women, because the prevalence of blood loss of at least $1000 \mathrm{ml}$ was lower than expected, the trial was underpowered for the evaluation of this outcome. It will be important for the WHO guideline development group to consider the trial results as a whole and in the context of all available evidence regarding the safety, cost-effectiveness, and affordability of heat-stable carbetocin. Widmer et al. note that Ferring Pharmaceuticals and Merck have an agreement with the WHO to make heat-stable carbetocin available in "public sector facilities of high-burden countries at an affordable and sustainable price." What this really means is unclear. The agreement ought to be made publicly available so that its implications for mothers everywhere can be considered. The efficacy and safety of carbetocin therapy for labor induction and postpartum hemorrhage are still unclear, and oxytocin is still indicated for these purposes, pending the availability of more data.

The second trial reported in this issue of the Journal, which was conducted by Sentilhes et al., ${ }^{6}$ had the same objective but targeted a different biologic mechanism. Tranexamic acid reduces bleeding by inhibiting the enzymatic breakdown of fibrin blood clots. ${ }^{7}$ It is widely used in surgery to reduce the incidence of blood transfusion, and early administration reduces the risk of death due to bleeding among patients with trauma. ${ }^{8,9}$ Tranexamic acid is heat-stable, inexpensive, and widely available and has a long shelf life. ${ }^{10,11}$ The World Maternal Antifibrinolytic (WOMAN) trial, for which we were investigators, showed that the early administration of tranexamic acid led to a lower risk of death due to bleeding than placebo among women with postpartum hemorrhage and had an acceptable safety profile. ${ }^{12}$ The treatment was similarly effective when bleeding was attributable to uterine atony. ${ }^{12}$ However, for many women in low- and middle-income countries, treatment comes too late. Most mothers in such countries have anemia, and many have severe anemia. In these women, postpartum bleeding is likely to be dangerous, leading to exsanguination within hours after delivery. Could the prophylactic use of tranexamic acid reduce the risk of postpartum hemorrhage?

The Tranexamic Acid for Preventing Postpartum Hemorrhage Following a Vaginal Delivery (TRAAP) trial enrolled more than 4000 women with a planned vaginal delivery of a singleton live fetus at 35 weeks or more of gestation who were at low risk for postpartum hemorrhage. Participants were randomly assigned to receive $1 \mathrm{~g}$ of tranexamic acid or matching placebo, administered by intravenous infusion immediately after the administration of oxytocin. The use of tranexamic acid did not result in a risk of the primary outcome - blood loss of at least $500 \mathrm{ml}$ - that was significantly lower than the risk with placebo (relative risk, 0.83 ; $95 \%$ confidence interval, 0.68 to $1.01 ; \mathrm{P}=0.07$ ). There were significantly lower rates of provider-assessed clinically significant postpartum hemorrhage and receipt of additional uterotonic agents in the tranexamic acid group than in the placebo group, but such results were not observed with regard to other bleeding-associated outcomes. The rates of nausea and vomiting were higher in the tranexamic acid group than in the placebo group. Although this trial was larger than previous trials of tranexamic acid for the prevention of postpartum hemorrhage, it cannot rule out a modest but clinically important treatment benefit, particularly in women at high risk for postpartum hemorrhage.

In summary, the results of the CHAMPION trial suggest that carbetocin can be used for the prevention of postpartum hemorrhage in situations in which maintaining a cold chain is difficult. However, its effects have not yet been studied in other scenarios in which oxytocin is used, and it will be critical to ensure that carbetocin is truly affordable and sustainable. As for tranexamic acid therapy, the TRAAP trial did not show a significantly lower incidence of postpartum hemorrhage with the active drug than with placebo, and at this point we would not 
recommend its use to prevent postpartum hemorrhage; larger trials involving women at high risk for postpartum hemorrhage will be useful in determining its value in prevention. The WOMAN-2 trial (ClinicalTrials.gov number, NCT03475342), which we are investigators for, is planned to quantify the effect of tranexamic acid therapy on postpartum hemorrhage and other maternal outcomes in 10,000 women with moderate or severe anemia.

Disclosure forms provided by the authors are available with the full text of this editorial at NEJM.org.

From the Clinical Trials Unit, London School of Hygiene and Tropical Medicine, London.

1. Say L, Chou D, Gemmill A, et al. Global causes of maternal death: a WHO systematic analysis. Lancet Glob Health 2014; 2(6):e323-e333.

2. WHO recommendations for the prevention and treatment of postpartum haemorrhage. Geneva: World Health Organization, 2012.

3. Westhoff G, Cotter AM, Tolosa JE. Prophylactic oxytocin for the third stage of labour to prevent postpartum haemorrhage. Cochrane Database Syst Rev 2013;10:CD001808.

4. Widmer M, Piaggio G, Nguyen TMH, et al. Heat-stable carbetocin versus oxytocin to prevent hemorrhage after vaginal birth. N Engl J Med 2018;379:743-52.
5. Malm M, Madsen I, Kjellström J. Development and stability of a heat-stable formulation of carbetocin for the prevention of postpartum haemorrhage for use in low and middle-income countries. J Pept Sci 2018;24(6):e3082.

6. Sentilhes L, Winer N, Azria E, et al. Tranexamic acid for the prevention of blood loss after vaginal delivery. $\mathrm{N}$ Engl J Med 2018;379:731-42.

7. Electronic Medicines Compendium. Summary of product characteristics: tranexamic acid (https://www.medicines.org.uk/ emc/product/1077/smpc).

8. Ker K, Edwards P, Perel P, Shakur H, Roberts I. Effect of tranexamic acid on surgical bleeding: systematic review and cumulative meta-analysis. BMJ 2012;344:e3054.

9. Roberts I, Shakur H, Afolabi A, et al. The importance of early treatment with tranexamic acid in bleeding trauma patients: an exploratory analysis of the CRASH-2 randomised controlled trial. Lancet 2011;377:1096-1101, 1101.e1-1101.e2.

10. de Guzman R, Polykratis IA, Sondeen JL, Darlington DN, Cap AP, Dubick MA. Stability of tranexamic acid after 12-week storage at temperatures from $-20^{\circ} \mathrm{C}$ to $50^{\circ} \mathrm{C}$. Prehosp Emerg Care 2013;17:394-400

11. Li B, Miners A, Shakur H, Roberts I. Tranexamic acid for treatment of women with post-partum haemorrhage in Nigeria and Pakistan: a cost-effectiveness analysis of data from the WOMAN trial. Lancet Glob Health 2018;6(2):e222-e228.

12. WOMAN Trial Collaborators. Effect of early tranexamic acid administration on mortality, hysterectomy, and other morbidities in women with post-partum haemorrhage (WOMAN): an international, randomised, double-blind, placebo-controlled trial. Lancet 2017;389:2105-16.

DOI: $10.1056 /$ NEJMe1808500

Copyright (๑) 2018 Massachusetts Medical Society. 